\title{
PELATIHAN (WORKSHOP) DAN SOSIALISASI MENGENAI TANAMAN HIDROPONIK DI KELURAHAN KEBON PALA KOTA ADMINISTRASI JAKARTA TIMUR TAHUN 2021 \\ Ulinata $^{1}$, Grace Putri Dianty ${ }^{2}$, Array Evangelista Nanjan ${ }^{3}$, Maria Febronia Penate Boik ${ }^{4}$ Ketmoen, Dea Cosella \\ Universitas Kristen Indonesia, Jakarta, Indonesia ${ }^{12345}$ \\ Email : ulinata@uki.ac.id; gdianty@gmail.com; arayevangelistan99@gmail.com; mariafebronia19@gmail.com; deacossellalidin@gmail.com
}

\begin{abstract}
Abstrak
Program Studi Arsitektur Fakultas Teknik UKI melakukan kegiatan Pengabdian kepada Masyarakat dengan melanjutkan kegiatan Pengabdian kepada Masyarakat sebelumnya dengan tema Green Action 23 : Pelatihan (Workshop) dan Sosialiasi Mengenai Tanaman Hidroponik di Kelurahan Kebon Pala Kota Administrasi Jakarta Timur Tahun 2021 yang sebelumnya diadakan hanya di RW 09 saja. Kegiatan Pengabdian kepada Masyarakat ini bertujuan untuk memberikan edukasi mengenai bagaimana cara menanam hidroponik dan apa saja manfaatnya. Metodenya adalah mengadakan Pelatihan (Workshop) dan Sosialiasi mengenai tanaman hidroponik dengan mengundang narasumber yang pakar di bidang hidroponik sehingga para peserta memperoleh edukasi mengenai bagaimana cara menanam hidroponik, beserta manfaatnya sehingga peserta dapat secara mandiri menanam hidroponik dan menularkannya kepada tetangga di lingkungan sekitar, kerabat dan keluarganya. Prosesnya dengan mempraktekkan langsung kepada peserta dengan menggunakan alat dan bahan yang disediakan diantaranya bak nutrisi dan tutup bak hidroponik, pupuk nutrisi $A B$ mix puriegarden, suntikan menakar nutrisi, benih, netpot bersumbu, kain kasa, tusuk gigi, selang, netpot bersumbu, airator, flanel potong, rockwool, TDS yang dibagikan kepada para peserta dan memberikan sesi tanya jawab kepada para peserta. Hasilnya menunjukkan bahwa setiap RW di Kelurahan Kebon Pala tersebut mengikuti Pelatihan (Workshop) secara keseluruhan sehingga materi yang disampaikan dapat dipahami dan berhasil mempraktikkan di rumah masing-masing peserta secara mandiri.
\end{abstract}

Kata Kunci : Green Action, Hidroponik, Kebon Pala

\begin{abstract}
The Architecture Study Program of Faculty of Engineering UKI carried out Community Service activities by continuing the previous Community Service activities with the theme Green Action 23: Training (Workshop) and Socialization Regarding Hydroponic Plants in Kebon Pala Village, East Jakarta Administration City in 2021 which previously was held only in RW 09 just. This Community Service activity aims to provide education about how to grow hydroponics and what are the benefits. The method is to hold a Training (Workshop) and Socialization on hydroponic plants by inviting resource persons who are experts in the field of hydroponics so that participants receive education about how to grow hydroponics, along with its benefits so that participants can plant hydroponics by them selves and pass it on to neighbors in the surrounding environment, friends and their families. The process is by direct practice to participants using the tools and materials provided, including nutrient tanks and hydroponic tub covers, nutrient fertilizer $A B$ mix puriegarden, nutrient measuring injections, seeds, wick netpot, gauze, toothpicks, hoses, wick netpot, airator, flannel. pieces, rockwool, TDS which were distributed to the participants and gave a question and answer session to the participants. The results showed that each RW in Kebon Pala Village participated in a total workshop so that the material presented could be understood and successfully practiced at each participant's home by themselves.
\end{abstract}

Key words : Green Action, Hydroponic, Kebon Pala 
PENDAHULUAN

Program Studi Arsitektur

Fakultas Teknik Universitas Kristen

Indonesia berusaha mewujudkan visi misinya maka dengan melakukan kegiatan Pengabdian Pada Masyarakat dengan judul Green Action 23 Pelatihan (Workshop) Mengenai Tanaman Hidroponik di Kelurahan Kebon Pala Kota Administrasi Jakarta Timur 2021 yang diadakan secara rutin tiap semester (Siahaan et al., 2019). Kegiatan ini juga merupakan kegiatan berkelanjutan yang telah diadakan sebelumnya yang hanya diadakan di RW 09 saja. Untuk itulah, Dosen dan Mahasiswa kembali mengadakan kegiatan Pengabdian kepada Masyarakat dengan memberikan Pelatihan (Workshop) Mengenai Tanaman Hidroponik di Kelurahan Kebon Pala Kota Administrasi Jakarta Timur 2021 yang diharapkan dapat menambah wawasan mengenai tanaman hidroponik bagi para peserta yang hadir.

Kegiatan ini terdiri dari beberapa rangkaian acara yaitu pembagian alat dan bahan untuk seluruh peserta yang hadir, Pelatihan (Workshop) Mengenai Tanaman Hidroponik dengan mengundang narasumber yang pakar di bidang hidroponik yang ditutup dengan sesi tanya jawab.

Hidroponik adalah sistem budidaya yang tidak menggunakan media tanah dan cocok diaplikasikan di area yang lahannya tidak begitu luas (Ulinata et al., 2021). Menanam hidroponik juga memiliki manfaat yang dapat dirasakan oleh masyarakat diantaranya untuk mengatasi keterbatasan lahan di daerah perkotaan jika ingin bercocok tanam atau bertani dengan hasil panen lebih cepat, memenuhi kebutuhan gizi agar dapat mengkonsumsi sayuran sehat tanpa bahan kimia dan juga dapat dijadikan bisnis sehingga dapat menjadi sumber penghasilan tambahan (Sudarmo, Agnes Puspitasari, 2018). Hasil yang diperoleh dari menanam secara hidroponik pada lahan permukiman sendiri lebih optimal dibanding cara lainnya (Wachdijono et al., 2019). Selain itu juga, aktivitas menanam hidroponik juga dapat menghilangkan rasa jenuh akibat wfh berkepanjangan selama pandemik Covid 19.

Diharapkan dengan adanya kegiatan ini, masyarakat di Kelurahan Kebon Pala Kota Administrasi Jakarta Timur memiliki aktivitas menanam tanaman hidroponik yang manfaatnya 
bisa menjadi bahan pangan sendiri, bisa juga menjadi bisnis untuk meningkatkan ekonomi khususnya di era Pandemik COVID 19 ini serta dapat menjadikan kampung hijau secara perlahan di Kelurahan Kebon Pala tersebut.

Kegiatan Pengabdian Kepada Masyarakat ini terdiri dari beberapa rangkaian acara diantaranya diantaranya sosialisasi dengan mengundang narasumber yang berkompeten di bidang tanaman hidroponik kepada masyarakat di Kelurahan Kebon Pala Kota Administrasi Jakarta Timur, tanya jawab, kemudian mengadakan pelatihan (workshop) pembuatan tanaman hidroponik.

Kegiatan Pengabdian Kepada Masyarakat ini melibatkan mahasiswa Program Studi Arsitektur Fakultas Teknik Universitas Kristen Indonesia Angkatan 2018 dan angkatan 2020 yang diharapkan mampu mengedukasi masyarakat mengenai tanaman hidroponik dan membangkitkan semangat masyarakat dalam mewujudkan kampung hijau yaitu dengan berkreasi dengan tanaman hidroponik sehingga permasalahan yang muncul pada era Pandemik COVID19 dapat teratasi.

\section{METODE}

Agar Pelaksana Tim Pengabdian kepada Masyarakat di Program Studi Arsitektur Fakultas Teknik UKI dapat menyampaikan dan memberikan pengaruh positif mengenai tanaman hidroponik sehingga diperlukan untuk melakukan kegiatan sosialisasi berupa pembekalan materai dan pelatihan (workshop). Sosialisasi dapat diartikan sebagai proses pengaruh, dipengaruhi, dan mempengaruhi kegiatan yang dengannya setiap individu dapat menyesuaikan diri (Science \& Volume, 2018).

Beberapa metode yang dipakai pada kegiatan Pengabdian Kepada Masyarakat yang berjudul Green Action 23 Pelatihan (Workshop) dan Sosialiasi Mengenai Tanaman Hidroponik di Kelurahan Kebon Pala Kota Administrasi Jakarta Timur Tahun 2021 adalah sebagai berikut :

METODE PEMILIHAN LOKASI Penulis menentukan lokasi Pengabdian Kepada Masyarakat dimana sebelumnya lokasi ini telah dilakukan program Pengabdian Kepada Masyarakat sebelumnya yaitu di RW 09. Saat ini Penulis memperluas kegiatan. Pengabdian 
Kepada Masyarakat di Kelurahan Kebon Pala Kota Administrasi Jakarta Timur dengan mengikutsertakan perwakilan setiap RW di Kelurahan tersebut menjadi peserta dalam kegiatan tersebut. Kegiatan ini diadakan di Aula Lantai 3 Kantor Lurah Kebon Pala dengan menjalankan protokol kesehatan yaitu menggunakan masker, menjaga jarak, menggunakan hand sanitizer.

\section{METODE PELAKSANAAN}

Selanjutnya untuk menyusun laporan kegiatan ini digunakan metode pelaksanaan yang terdiri dari beberapa tahap yaitu:

1. Mengadakan pertemuan kepada Bapak Lurah Kebon Pala, Ibu Lurah Kebon Pala yang sekaligus menjadi Ketua Tim Penggerak PKK di Kelurahan Kebon Pala.

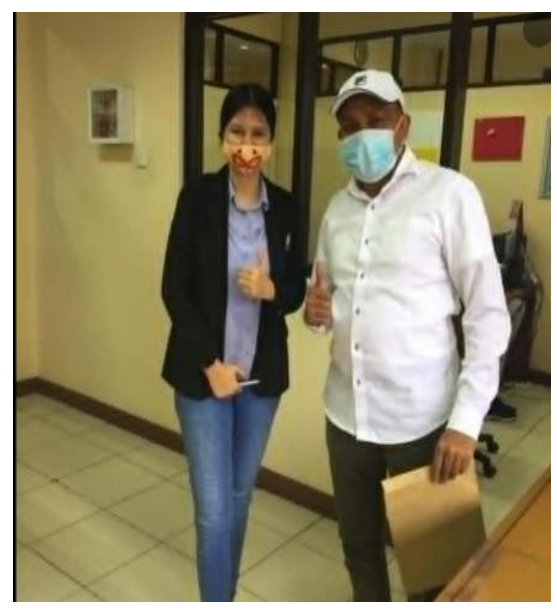

Gambar 1. Foto Bersama Bapak Lurah Kebon Pala
2. Mengadakan sosialisasi di Aula It.3 Kelurahan Kebon Pala dengan

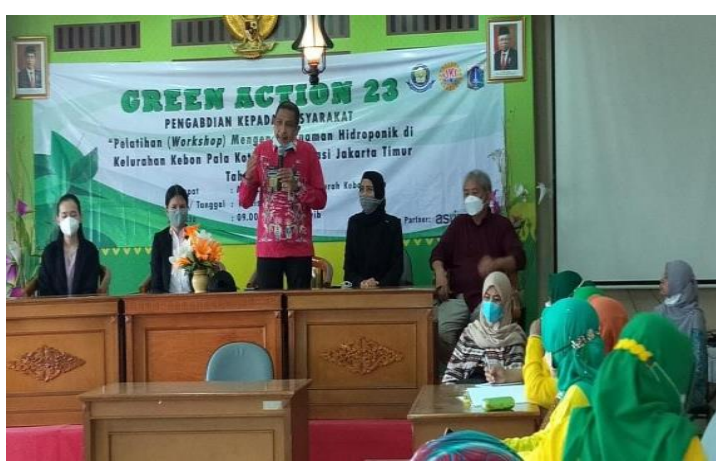

mengundang perwakilan sebanyak maksimal 2 peserta di setiap RW yang terdiri atas 13 kelompok.

Gambar 2. Bapak Lurah Kebon Pala Hadir dan Memberikan Kata Sambutan di Acara Sosialisasi

3. Membeli bahan dan alat-alat yang diperlukan dan dibagikan ke masing-masing peserta untuk dipakai selama kegiatan pelatihan (workshop) dan sosialisasi berlangsung.

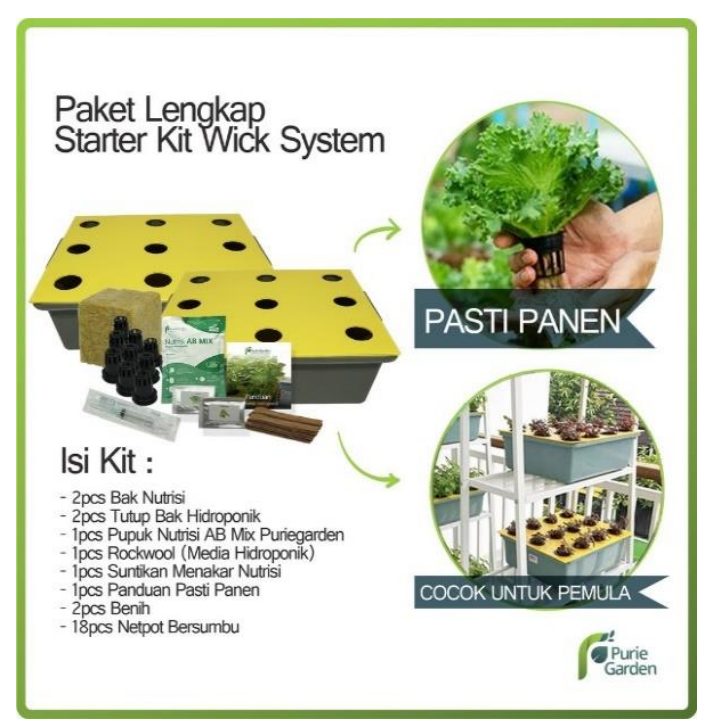

Gambar 2. Alat dan Bahan Menanam Hidroponik 
4. Mengundang Narasumber yaitu Bapak Ir.Ronny Tanumihardja yang merupakan arsitek sekaligus pakar hidroponik skala nasional.

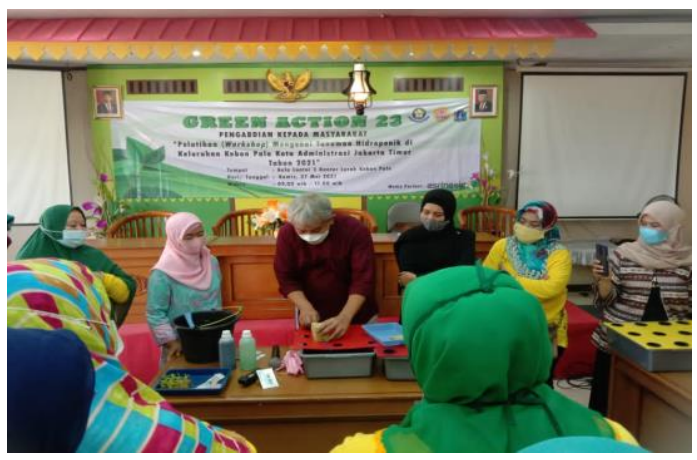

Gambar 3. Narasumber Sedang Mempraktikkan Cara Menanam Hidroponik

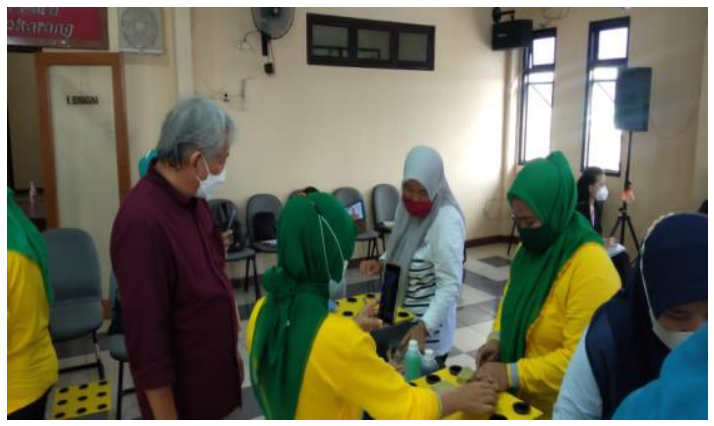

5. Mengadakan sesi tanya jawab.

\section{Gambar 4. Peserta bertanya (diskusi) Bersama Narasumber}

Pelaksanaan

kegiatan

Pengabdian Kepada Masyarakat yang berjudul Green Action 23 Pelatihan (Workshop) dan Sosialiasi Mengenai Tanaman Hidroponik di Kelurahan Kebon Pala Kota Administrasi Jakarta Timur Tahun 2021 ini dilakukan oleh Dosen dan Mahasiswa Program Studi
Arsitektur Fakultas Teknik Universitas kristen Indonesia.

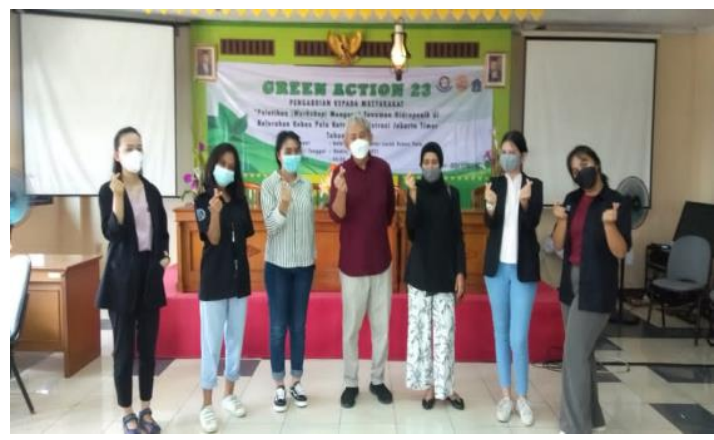

Gambar 5. Foto Bersama Para Dosen, Mahasiswa, Narasumber dan Ibu Lurah Kebon Pala yang Sekaligus Menjadi Ketua Tim PKK

\section{HASIL DAN PEMBAHASAN}

Kegiatan Pengabdian Kepada Masyarakat yang berjudul Green Action 23 Pelatihan (Workshop) dan Sosialiasi Mengenai Tanaman Hidroponik di Kelurahan Kebon Pala Kota Administrasi Jakarta Timur Tahun 2021 ini dihadiri oleh 13 kelompok yang terdiri dari 2 peserta dari masing-masing RW di Kelurahan Kebon Pala Kota Administrasi Jakarta Timur. Panitia Pelaksana kegiatan Pengabdian Kepada Masyarakat membeli alat-alat dan bahan terselebih dahulu untuk dibagikan kepada seluruh peserta nantinya. Alat-alat dan bahan tersebut adalah bak nutrisi dan tutup bak hidroponik, pupuk nutrisi $A B$ mix Puriegarden, Suntikan Menakar Nutrisi, Benih, Netpot Bersumbu, Kain Kasa, Tusuk 
Gigi, Selang, Netpot Bersumbu, Airator, Flanel potong, Rockwool, TDS.

Setelah alat-alat dan bahan dibeli, Panitia Pelaksana membagikan alat-alat dan bahan yang akan dipakai saat Pelatihan (Workshop) dan Sosialiasi berlangsung dua hari sebelum kegiatan dimulai.

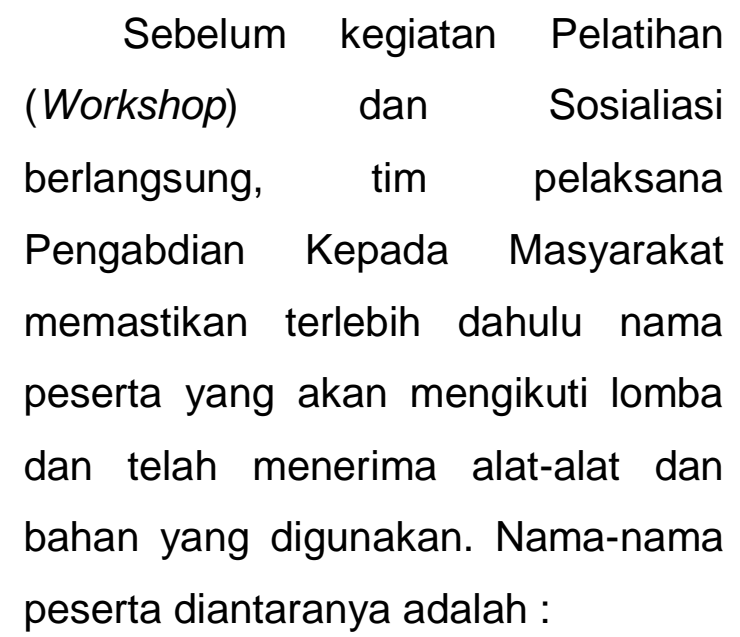

1. Nurlailah

2. Syamsiana

3. Priyanti

4. Sumilah

5. Duwi Tantie

6. Martijah Isnaini

7. Wida Ariyastuti

8. Yunani

9. Julaeha

10. Wiwi Wiharyati

11. Turminah

12. Nina Kurniasari

13. Parminah

14. Nurhayati
15. Devi Nurlela

16. Sri Hartuti

17. Suparmi

18. Sri Rahayu

19. Fitri.A

20. Murtanti

21. Hariyati

22. Puji Rahayu

23. Estri Prasetyawati

24. Jemini

25. Sri Hastuti

26. Achmad Chaerudin

Setelah memastikan seluruh peserta mendapatkan alat dan bahan yang akan digunakan, lalu narasumber menyampaikan materi mengenai tanaman hidroponik.

Materi yang disampaikan mengenai proses menanam diantaranya proses menanam hidroponik melalui beberapa tahapan yaitu penyemaian (pembibitan), Pemindahan Bibit Tanaman, Pemeliharaan /perawatan kemudian memastikan volume air di dalam bak yang dipompakan cukup (tidak boleh di bawah permukaan pompa), cek kadar kandungan nutrisi (ppm) dan menambahkan nutrisi secukupnya sesuai usia tanaman hingga waktunya panen dimana hasil panennya bisa menjadi bahan pangan sendiri atau dijual dengan kemasan menarik. 
Setelah narasumber menyampaikan materinya, para peserta diberikan kesempatan untuk bertanya kepada narasumber apabila ada yang yang perlu ditanyakan. Kegiatan ini diliput dan dipublikasikan di media online Asrinesia.

\section{UCAPAN TERIMA KASIH}

Puji dan syukur Penulis panjatkan ke hadirat Tuhan Yang Maha Esa, karena berkat rahmat dan karunia-Nya Penulis dapat menyelesaikan seluruh proses penyusunan Laporan Program Pengabdian Pada Masyarakat Program Studi Arsitektur Fakultas Teknik UKI di tahun 2021 ini yang berjudul Green Action 23 Pelatihan (Workshop) Mengenai Tanaman Hidroponik di Kelurahan Kebon Pala Kota Administrasi Jakarta Timur 2021. Penulis mengucapkan terimakasih kepada :

1. Bapak Dr. Dhaniswara K. Harjono, SH., MH., MBA, sebagai Rektor Universitas Kristen Indonesia.

2. Ibu Ir.Galuh Widati, M.Sc, sebagai Dekan Fakultas Teknik Universitas Kristen Indonesia.

3. Bapak Ir.Sahala Simatupang, MT, sebagai Ketua Program
Studi Arsitektur Universitas Kristen Indonesia.

4. Bapak Lurah Kelurahan Kebon Pala Kota Administrasi Jakarta Timur yaitu Bapak Ir.Faisal Rizal, M.Kes

5. Ibu Elvira selaku lbu Lurah Kebon Pala Kota Administrasi Jakarta Timur sekaligus menjadi Ketua Tim Penggerak PKK di Kelurahan Kebon Pala Kota Administrasi Jakarta Tim

6. Tim Pelaksana Pengabdian pada Masyarakat : Ibu Ulinata, ST.Ars., MT, Bapak Ir.Bambang Erwin, MT, Bapak Ir. Riyadi Ismanto, M.Arch, Grace Putri Dianty, ST., M.Ars.

7. Mahasiswa yang ikut serta yaitu 8. Para peserta Pelatihan (Workshop) dan Sosialisasi di Kelurahan Kebon Pala, Kota Administrasi Jakarta Timur khususnya yang sudah meluangkan waktu dan tenaga dan pikirannya untuk mengikuti Pelatihan (Workshop) dan Sosialisasi di Kelurahan Kebon Pala, Kota Administrasi Jakarta Timur 2021.

9. Rekan Dosen Program Studi Arsitektur Fakultas Teknik UKI yang berpartisipasi untuk 
mendukung

Program

Pengabdian kepada Masyarakat

Program Studi Arsitektur

Fakultas Teknik UKI di tahun 2021 ini yang berjudul Green Action 23 : Pelatihan (Workshop) dan Sosialiasi Mengenai Tanaman Hiidroponik di Kelurahan Kebon Pala Kota Administrasi Jakarta Timur Tahun 2021.

10. Asrinesia yang sudah meliput dan mempublish ke media online Asrinesia dalam kegiatan Program Pengabdian kepada Masyarakat Program Studi Arsitektur Fakultas Teknik UKI yang berjudul Green Action 23 : Pelatihan (Workshop) dan Sosialiasi Mengenai Tanaman Hiidroponik di Kelurahan Kebon Pala Kota Administrasi Jakarta Timur Tahun 2021.

11. Semua pihak yang tidak dapat disebutkan satu per satu karena telah berpartisipasi untuk mensukseskan Program

Pengabdian kepada Masyarakat ini.

Semoga laporan hasil kegiatan Program Pengabdian kepada Masyarakat ini dapat bermanfaat bagi kita semua khususnya di lingkungan
Program Studi Arsitektur Fakultas Teknik UKI.

\section{REFERENSI}

Science, S., \& Volume, T. (2018). No Title. 2.

Siahaan, U., Eni, S. P., \& Ulinata. (2019). Pengurangan Volume Sampah Dengan Memanfaatkan Dan Mendaur Ulang Sampah Melalui Kegiatan Pembuatan Pupuk Organik-Kompos. JURNAL ComunitÃ Servizio: Jurnal Terkait Kegiatan Pengabdian Kepada Masyarakat, Terkhusus Bidang Teknologi, Kewirausahaan Dan Sosial Kemasyarakatan, 1(1), 1-10. https://doi.org/10.33541/cs.v1i1.9 48

Sudarmo, Agnes Puspitasari, D. (2018). Pemanfaatan Pertanian Secara Hidroponik untuk Mengatasi Keterbatasan Lahan Pertanian di Daerah Perkotaan. Seminar Nasional Pengabdian Kepada Masyarakt Universitas Terbuka, 1-8. http://repository.ut.ac.id/8034/1/1 -8 Agnes Puspitasari Sudarmo.pdf 
Volume 3, Nomor 2, Tahun 2021 Hal 621 - 629

Ulinata, U., Dianty, G. P., Hasugian, A.

E., \& Kidingallo, E. K. (2021).

Lomba Kreativitas Tanaman

Hidroponik sebagai Strategi

dalam Mewujudkan Kampung

Hijau di RW 09 Kelurahan Kebon

Pala Kota Administrasi Jakarta

Timur.

JURNAL

ComunitÃ Servizio: Jurnal

Terkait Kegiatan Pengabdian

Kepada Masyarakat, Terkhusus

Bidang

Teknologi,

Kewirausahaan Dan Sosial

Kemasyarakatan, 3(1), 499-507.

https://doi.org/10.33541/cs.v3i1.2

755

Wachdijono, W., Wahyuni, S., \&

Trisnaningsih, U. (2019).

Sosialisasi Urban Farming

Melalui Budidaya Tanaman

Sayuran Secara Vertikultur Dan

Hidroponik Di Kelurahan Kalijaga,

Kecamatan Harjamukti, Kota

Cirebon. Qardhul Hasan: Media

Pengabdian Kepada Masyarakat,

5(2), $\quad 90$.

https://doi.org/10.30997/qh.v5i2.

1928 